\title{
Slackia piriformis sp. nov. and Collinsella tanakaei sp. nov., new members of the family Coriobacteriaceae, isolated from human faeces
}

\author{
Fumiko Nagai, Yohei Watanabe and Masami Morotomi \\ Yakult Central Institute for Microbiological Research, 1796 Yaho, Kunitachi, 186-8650 Tokyo, \\ Japan
}

Correspondence

Masami Morotomi

masami-morotomi@yakult.co.jp
Three Gram-positive, strictly anaerobic, non-spore-forming, rod-shaped organisms (strains YIT $12062^{\top}$, YIT $12063^{\top}$ and YIT 12064) were isolated from human faeces. Strain YIT $12062^{\top}$ was asaccharolytic and possessed a DNA G+C content of 58.3 mol\%. Cells of strain YIT $12062^{\top}$ were negative for catalase, oxidase, urease, hydrolysis of aesculin and gelatin, nitrate reduction and indole production. Based on 16S rRNA gene sequence analysis, strain YIT $12062^{\top}$ was assigned to the genus Slackia (91.7-96.0\% sequence similarities to type strains of Slackia species). Biochemical data showed that the isolate was phenotypically distinct from all recognized species of the genus Slackia. Strain YIT $12062^{\top}$ therefore represents a novel species in the genus Slackia, for which the name Slackia piriformis sp. nov. is proposed. The type strain is YIT $12062^{\top}$ (=DSM $22477^{\top}=\mathrm{JCM} 16070^{\top}$ ). Following 16S rRNA gene sequence analysis, strains YIT $12063^{\top}$ and YIT 12064, which were isolated from different subjects, were shown to be most closely related to species of the genus Collinsella (93.8-95.1\% similarities to type strains). Although their phenotypic characteristics were very similar and they shared $>99 \% 16 \mathrm{~S}$ rRNA gene sequence similarity and $>97 \pm 1.8 \%$ DNA-DNA relatedness, the two isolates could be discriminated by RAPD fingerprints. The DNA G+C contents of strains YIT $12063^{\top}$ and YIT 12064 were 60.8 and 61.0 mol\%, respectively. They were saccharolytic in API test systems, positive for aesculin hydrolysis and negative for catalase, oxidase, urease, indole production, nitrate reduction and gelatin hydrolysis. The major end products of glucose fermentation of these strains were lactate, acetate and formate. Biochemical data supported the affiliation of strains YIT $12063^{\top}$ and YIT 12064 to the genus Collinsella and showed that they were phenotypically distinct from all recognized species of the genus Collinsella. Strains YIT $12063^{\top}$ and YIT 12064 therefore represent a novel species of the genus Collinsella, for which the name Collinsella tanakaei sp. nov. is proposed. The type strain is YIT $12063^{\top}\left(=\mathrm{DSM} 22478^{\top}=\mathrm{JCM} 16071^{\top}\right)$.
Some species belonging to the genera Slackia and Collinsella, together with Atopobium and Eggerthella, have been isolated from faecal samples from normal healthy subjects (Kageyama \& Benno, 2000; Matthies et al., 2009) or detected by using culture-independent approaches based on 16S rRNA diversity (Kassinen et al., 2007; Matsuki et al., 2002; Wang et al., 2004; Harmsen et al., 2000). All of these

\footnotetext{
Abbreviations: DMA, dimethyl acetal; ML, maximum-likelihood; MP, maximum-parsimony; RAPD, random amplified polymorphic DNA.

The GenBank/EMBL/DDBJ accession numbers for the 16S rRNA gene sequences of strains YIT 12062 ${ }^{\top}$, YIT $12063^{\top}$ and YIT 12064 are AB490806, AB490807 and AB490808, respectively.

RAPD-PCR fingerprinting of the two novel Collinsella isolates (Fig. S1), fatty acid compositions of strain YIT $12062^{\top}$ and the type strains of Slackia species (Table S1) and fatty acid compositions of strains YIT $12063^{\top}$, YIT 12064 and other members of the genus Collinsella (Table S2) are available with the online version of this paper.
}

genera are within the family Coriobacteriaceae in the phylum Actinobacteria. Currently, five species of the genus Slackia have been described: Slackia exigua, S. heliotrinireducens, $S$. faecicanis, $S$. isoflavoniconvertens and $S$. equolifaciens. S. exigua, previously known as Eubacterium exiguum (Poco et al., 1996; Wade et al., 1999), was isolated from human oral lesions. S. heliotrinireducens, previously known as Peptococcus heliotrinreducans, and S. faecicanis were isolated from the rumen of a sheep and canine faeces, respectively (Lanigan, 1976; Lawson et al., 2005). S. isoflavoniconvertens and S. equolifaciens, which produce equol, were recently isolated from human faeces by Matthies et al. (2009) and Jin et al. (2010), respectively. The genus Collinsella comprises only three recognized species, namely Collinsella aerofaciens, C. stercoris and $C$. intestinalis, all isolated from the faeces of healthy human subjects (Kageyama \& Benno, 2000; Holdeman et al., 1977). 
To better understand the physiological characteristics and function of the majority of the human gastrointestinal microbiota, we have performed several intensive cultivation trials aimed at isolating as-yet uncultured bacteria from the human gastrointestinal tract (Sakon et al., 2008; Morotomi et al., 2008, 2009, 2010; Nagai et al., 2009, 2010; Watanabe et al., 2010). Here, the isolation of novel species of the genera Slackia and Collinsella from the faeces of healthy Japanese adults is reported. Interestingly, the isolates showed $>99 \% 16 \mathrm{~S}$ rRNA gene sequence similarity to several cloned sequences originating from the faeces of human subjects and other mammals, suggesting that they are common members of the mammalian intestinal microbiota.

Faecal samples were collected from two healthy Japanese males (Subjects $\mathrm{H}$ and $\mathrm{K}$; aged 57 and 27 years, respectively) and immediately transferred to anaerobic conditions. Each sample was weighed and diluted with prereduced 0.1 M PBS ( $\mathrm{pH} 7$ ) in an anaerobic glove box (Coy Laboratory Products), which contained $88 \%$ nitrogen, $7 \%$ hydrogen and $5 \%$ carbon dioxide. Each dilution was then spread on modified Gifu anaerobic medium (GAM; Nissui Pharmaceutical) containing $1.5 \%(\mathrm{w} / \mathrm{v})$ agar and supplemented with bile, $\mathrm{NaCl}$ or antibiotics (described below) to isolate subdominant groups in the intestinal microbiota. The composition of the modified GAM agar was as described previously (Sakon et al., 2008).

Plates were incubated at $37{ }^{\circ} \mathrm{C}$ for 3 days. Strain YIT $12062^{\mathrm{T}}$ was isolated from a GAM agar plate supplemented with $6 \%$ Bacto oxgall (Difco) and inoculated with a $10^{-5}$ serially diluted faecal sample from subject $\mathrm{H}$. Strains YIT $12063^{\mathrm{T}}$ and YIT 12064 were isolated from a GAM agar plate supplemented with $1 \%(\mathrm{w} / \mathrm{v}) \mathrm{NaCl}$ and fosfomycin $\left(60 \mu \mathrm{g} \mathrm{ml}^{-1}\right)$ and inoculated with a $10^{-6}$ serially diluted faecal sample from subjects $\mathrm{H}$ and $\mathrm{K}$, respectively. Single colonies were picked and streaked on the modified GAM agar until pure cultures were obtained. The end products of bacterial metabolism of glucose in pre-reduced peptoneyeast extract medium (Holdeman et al., 1977) supplemented with $1 \%$ glucose (PYG medium) were analysed by HPLC, as described previously (Chonan et al., 1995). Cellular morphology was examined by phase-contrast light microscopy of 4-day-old modified GAM agar cultures. Biochemical characteristics were determined in duplicate by using the API Rapid ID32A, API ZYM and API 20A systems (bioMérieux) according to the manufacturer's instructions. Sensitivity to bile was determined by comparing growth of the strains on modified GAM agar with and without $2 \%$ Bacto oxgall (Difco) after 5 days of incubation at $37{ }^{\circ} \mathrm{C}$.

Cellular fatty acid methyl esters were obtained from lyophilized cells grown on modified GAM agar (Slackia species) or grown in modified GAM broth supplemented with $1 \%$ glucose (Collinsella species) by saponification, methylation and extraction using minor modifications (Kuykendall et al., 1988) of the method of Miller (1982).
Fatty acid methyl esters were determined by the MIDI system using MOORE5 of the MIS Standard Libraries.

Isoprenoid quinones were extracted as described by Komagata \& Suzuki (1987) and were analysed by using an HPLC-atmospheric pressure chemical ionization-MS/ MS system (API 3200; Applied Biosystems) with an L column ODS $(2.1 \times 150 \mathrm{~mm}$; Chemicals Evaluation and Research Institute) according to a modification of the method of Katsuta et al. (2005).

The DNA G + C content was determined by hydrolysing the DNA enzymically and quantifying the nucleosides by HPLC according to the method of Ezaki et al. (1990). Fluorometric DNA-DNA hybridization in microdilution wells was carried out by the method of Ezaki et al. (1989). Details of isolation and purification of DNA were as described previously (Yuki et al., 2000).

PCR-based random amplified polymorphic DNA (RAPD) fingerprinting was carried out by the method of Akopyanz et al. (1992) using primer 5'-AACGCGCAAC-3'. The PCR products were subjected to agarose gel electrophoresis.

The 16S rRNA genes of the isolates were amplified by PCR using universal primers 8F (5'-AGAGTTTGATCMTGGCTCAG-3'; Miyake et al., 1998) and 15R (5'-AAGGAGGTGATCCARCCGCA-3'; Yuki et al., 2000) and direct sequencing of the amplified DNA fragments was performed. Details of these procedures have been described previously (Miyake et al., 1998). 16S rRNA gene sequences of reference species were retrieved from GenBank/EMBL/ DDBJ by using the FASTA program (Lipman \& Pearson, 1985). Sequences were aligned and used to produce an unrooted phylogenetic tree according to the neighbourjoining method (Saitou \& Nei, 1987) by using CLUSTAL_X (version 1.83) (Thompson et al., 1997). The stability of the groupings was estimated by bootstrap analysis (1000 replications). All phylogenetic trees were visualized by using the program TreeView version 1.6.6 (Page, 1996). Maximum-parsimony (MP) and maximum-likelihood (ML) methods were used to confirm the phylogenetic placement of the aligned sequences. MP analysis was performed using the software package MEGA4 (Tamura et al., 2007). The ML tree was constructed via the PHYML program (Guindon \& Gascuel, 2003) by using Kimura's two-parameter nucleotide substitution model (Kimura, 1980). The input file was prepared via the program SEQBOOT within the PHYLIP package (Felsenstein, 2004).

Cells of YIT $12062^{\mathrm{T}}$ were Gram-positive, obligately anaerobic and non-motile and formed chains of pearshaped to irregularly shaped rods $(0.4-1.1 \times 0.9-2.6 \mu \mathrm{m})$. After 4 days anaerobic incubation at $37{ }^{\circ} \mathrm{C}$ on modified GAM agar, colonies were $0.1-1.0 \mathrm{~mm}$ in diameter, translucent to beige, and circular, with an uneven surface and irregular edges. Growth of strain YIT $12062^{\mathrm{T}}$ in PYG broth was weak and no major acids were detected as end products of metabolism. Strain YIT $12062^{\mathrm{T}}$ and S. faecicanis YIT $12015^{\mathrm{T}}$ were able to grow on medium 
containing $2 \%$ oxgall, but the number of colonies decreased to about $50 \%$ and $5 \%$, respectively, compared with the control medium without oxgall (Table 1). In contrast, the type strains of S. exigua and S. heliotrinireducens did not grow on the oxgall-containing medium (Table 1). Strain YIT $12062^{\mathrm{T}}$ and the type strains of $S$. exigua, S. heliotrinireducens and S. faecicanis were asaccharolytic in the API test systems. Indole production, nitrate reduction, catalase, urease and hydrolysis of aesculin and gelatin were negative in all of these strains. Other biochemical characteristics obtained by using the API Rapid ID32A and API ZYM test systems are included in the species description of Slackia piriformis sp. nov.

The fatty acid profiles of strain YIT $12062^{\mathrm{T}}$ and the type strains of species of the genus Slackia are detailed in
Supplementary Table S1 (available in IJSEM Online). All of these strains contained $\mathrm{C}_{18: 1} \omega 9 c(32-52 \%)$ and $\mathrm{C}_{18: 1} \omega 9 c$ dimethyl acetal (DMA) (16-24\%) as the predominant fatty acids. Although some minor qualitative and quantitative differences in fatty acid content could be observed, the overall patterns of the composition were very similar among species of this genus. Respiratory quinones were not detected in strain YIT $12062^{\mathrm{T}}$ or in the type strains of $S$. exigua, S. heliotrinireducens and S. faecicanis.

A $1463 \mathrm{bp}$ region of the $16 \mathrm{~S}$ rRNA gene of strain YIT $12062^{\mathrm{T}}$ was sequenced. Database searches of recognized taxa revealed that strain YIT $12062^{\mathrm{T}}$ was most closely related to species of the genus Slackia, with 16S rRNA gene sequence similarities of $91.7,92.6,92.6,92.8$ and $96.0 \%$ to the type strains of $S$. isoflavoniconvertens, S. exigua, $S$.

Table 1. Major characteristics of strain YIT $12062^{\top}$ and other members of the genus Slackia

Strains: 1, YIT $12062^{\mathrm{T}}$; 2, S. exigua YIT $10056^{\mathrm{T}}\left(=\mathrm{JCM} 11022^{\mathrm{T}}\right) ; 3$, S. heliotrinireducens YIT $12016^{\mathrm{T}}\left(=\mathrm{JCM} 14554^{\mathrm{T}}\right) ; 4$, S. faecicanis YIT $12015^{\mathrm{T}}$ $\left(=\mathrm{JCM} 14555^{\mathrm{T}}\right) ; 5$, S. isoflavoniconvertens DSM $22006^{\mathrm{T}} ; 6$, S. equolifaciens JCM $16059^{\mathrm{T}}$. Apart from S. isoflavoniconvertens (Matthies et al., 2009) and S. equolifaciens (Jin et al., 2010), data are from the present study unless otherwise indicated. +, Positive; -, negative; w, weak positive; v, variable; ND, no data available. In the API test systems, all strains were positive for arginine dihydrolase and naphthol-AS-BI-phosphohydrolase, but negative for alkaline phosphatase, $\alpha$-arabinosidase, $N$-acetyl- $\beta$-glucosaminidase, chymotrypsin, $\alpha$-fucosidase, $\alpha$-galactosidase, $\beta$-galactosidase, $\alpha$ glucosidase, $\beta$-glucosidase, $\beta$-glucuronidase, glutamic acid decarboxylase, glutamyl glutamic acid arylamidase, lipase (C14), $\alpha$-mannosidase, 6phospho- $\beta$-galactosidase, pyroglutamic acid arylamidase, trypsin and urease.

\begin{tabular}{|c|c|c|c|c|c|c|}
\hline Characteristic & 1 & 2 & 3 & 4 & 5 & 6 \\
\hline Isolation source & Human faeces & $\begin{array}{c}\text { Human oral } \\
\text { lesions }\end{array}$ & Rumen of sheep & Canine faeces & Human faeces & $\begin{array}{c}\text { Human } \\
\text { faeces }\end{array}$ \\
\hline Major products from $\mathrm{PYG}^{\star}$ & - & - & $\mathrm{a}$ & - & $\mathrm{ND}$ & $\mathrm{ND}$ \\
\hline Bile resistant & $\mathrm{w} \dagger$ & - & - & $\mathrm{w} \dagger$ & $\mathrm{ND}$ & $\mathrm{ND}$ \\
\hline \multicolumn{7}{|c|}{ API tests (API ZYM, Rapid ID32A) } \\
\hline Acid phosphatase & $\mathrm{w}$ & + & - & $\mathrm{w}$ & + & ND \\
\hline Alanine arylamidase & + & + & + & - & - & + \\
\hline Arginine arylamidase & - & + & - & - & - & - \\
\hline Cystine arylamidase & + & + & $\mathrm{V}$ & - & - & ND \\
\hline Esterase (C4) & - & - & - & $-\S$ & + & ND \\
\hline Leucyl glycine arylamidase & - & - & - & - & - & $\mathrm{V}$ \\
\hline Phenylalanine arylamidase & + & + & + & - & - & + \\
\hline Proline arylamidase & + & + & + & - & - & + \\
\hline Serine arylamidase & + & + & + & $+\S$ & - & + \\
\hline Tyrosine arylamidase & + & + & + & - & - & + \\
\hline Valine arylamidase & + & + & + & - & - & ND \\
\hline
\end{tabular}

${ }^{\star}$ Lower-case letters indicate $<1$ mequiv. of acid per $100 \mathrm{ml}$; a, acetic acid.

$\dagger$ Cells grew on medium containing $2 \%$ oxgall, but the number of colonies was decreased compared with the control medium without oxgall (see text for details).

$\$$ Data for DNA G + C content for S. exigua, S. heliotrinireducens, S. faecicanis, S. isoflavoniconvertens and S. equolifaciens are from Poco et al. (1996), Wade et al. (1999), Lawson et al. (2005), Matthies et al. (2009) and Jin et al. (2010), respectively.

§Data from this study were different from published data (Lawson et al., 2005). It is assumed that the culture conditions were different. 
heliotrinireducens, S. equolifaciens and S. faecicanis, respectively (Fig. 1).

Interestingly, at the time of writing, the $16 \mathrm{~S}$ rRNA gene sequences of 12 uncultured bacterial clones deposited in GenBank/EMBL/DDBJ had $>99 \%$ sequence similarity to that of strain YIT $12062^{\mathrm{T}}$. The isolation sources of these clones were faecal samples of human and other mammals. Some of them are shown in Fig. 1. Strain YIT $12062^{\mathrm{T}}$ displayed $>99 \% 16 \mathrm{~S}$ rRNA gene sequence similarity to some of the faecal uncultured clones from human subjects reported by Ley et al. (2006) (GenBank accession nos DQ800868 and DQ808704) and Turnbaugh et al. (2009) (accession no. FJ366859), and from armadillo (accession no. EU771928) reported by Ley et al. (2008) (Fig. 1).

Table 1 shows characteristics that can be used to differentiate strain YIT $12062^{\mathrm{T}}$ from members of the genus Slackia. The DNA G + C content of strain YIT $12062^{\mathrm{T}}$ was $58.3 \mathrm{~mol} \%$.

Cells of YIT $12063^{\mathrm{T}}$ were Gram-positive, obligately anaerobic, non-motile rods $(0.5-1.0 \times 1.0-3.3 \mu \mathrm{m})$ most often occurring in long chains. Cells of YIT 12064 were similar to those of YIT $12063^{\mathrm{T}}$, but occurred singly and only occasionally in pairs or short chains. Colonies of both strains after 4 days anaerobic incubation at $37{ }^{\circ} \mathrm{C}$ on modified GAM agar were $0.1-1.5 \mathrm{~mm}$ in diameter, entire, circular, beige or grey-beige and opaque. The major end products of glucose fermentation of strain YIT $12063^{\mathrm{T}}$ in PYG broth were lactic $(9.5 \mathrm{mM})$ and acetic $(2.5 \mathrm{mM})$ acids; small amounts of formic and succinic acids were also detected. On the other hand, glucose fermentation by strain YIT 12064 in PYG broth was very weak and small amounts of lactic, acetic and formic acids were detected. However, when grown in modified GAM broth, this strain was stimulated by glucose: large amounts of lactic $(28.9 \mathrm{mM})$, formic $(10.8 \mathrm{mM})$ and acetic $(9.8 \mathrm{mM})$ acids were detected after incubation in modified GAM broth supplemented with $1 \%$ glucose. Strains YIT $12063^{\mathrm{T}}$ and YIT 12064 were both resistant to $20 \%$ bile. They were saccharolytic in the API test system, positive for aesculin hydrolysis and negative for catalase, urease, oxidase, indole production, nitrate reduction and gelatin hydrolysis. Other biochemical characteristics obtained by using the API systems (API Rapid ID32A, API ZYM and API 20A) are included in the species description of Collinsella tanakaei sp. nov.

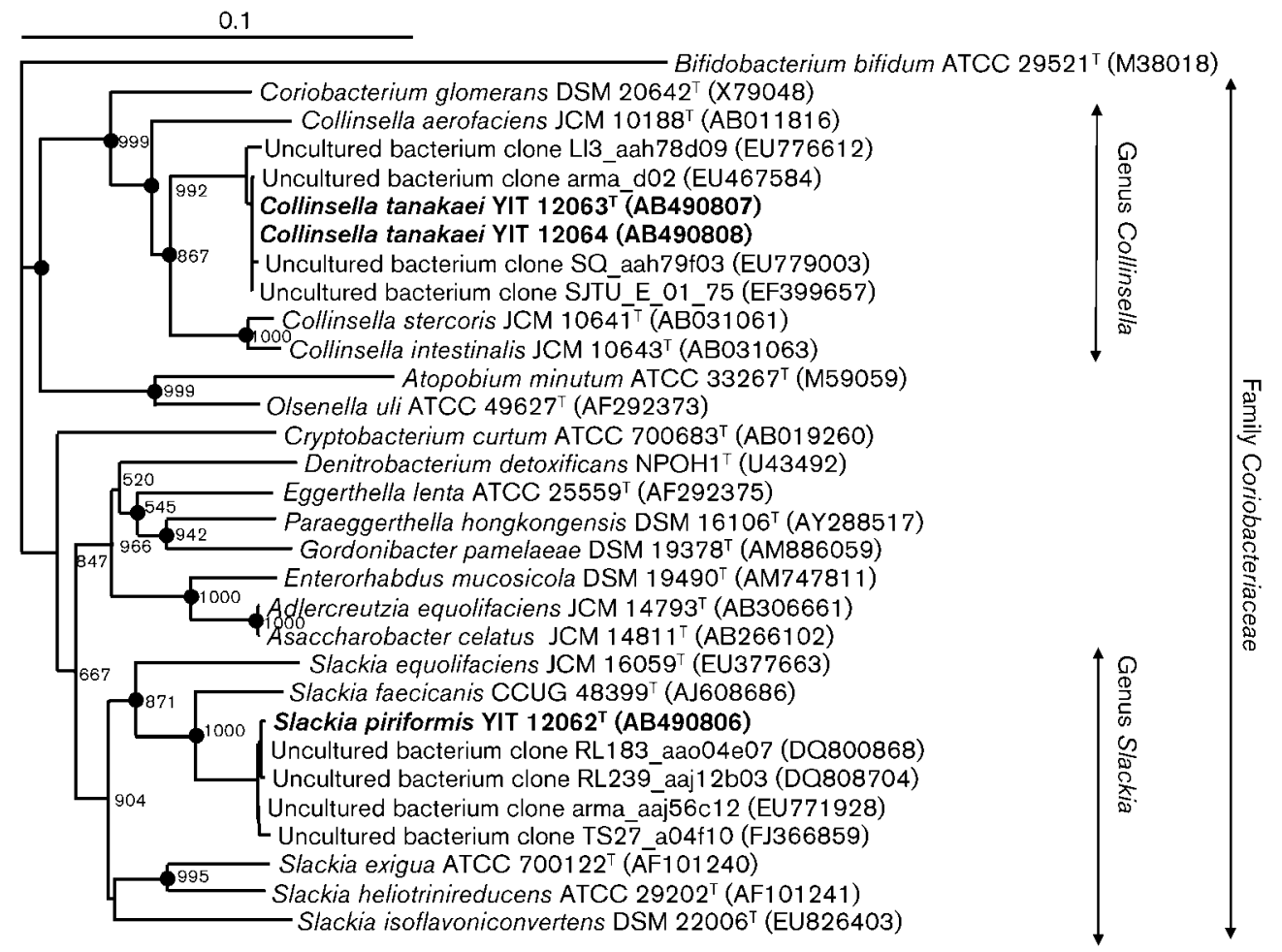

Fig. 1. Phylogenetic tree showing the positions of strains YIT $12062^{\top}$, YIT $12063^{\top}$, YIT 12064 and the type strains of species of the family Coriobacteriaceae based on 16S rRNA gene sequence analysis. The tree was rooted with Bifidobacterium bifidum ATCC $29521^{\top}$ and was constructed by using the neighbour-joining method and based on a comparison of approximately $1200 \mathrm{nt}$, with bootstrap values (>500) expressed as scores out of 1000 replications. Similar tree topologies were obtained by using the MP and ML methods (data not shown). Circles indicate that the corresponding nodes were also recovered in trees generated with the MP and ML methods. GenBank/EMBL/DDBJ accession numbers are shown in parentheses. Bar, 0.1 substitutions per nucleotide position. 
The fatty acid profiles of strains YIT $12063^{\mathrm{T}}$ and YIT 12064 and the type strains of species of the genus Collinsella are detailed in Supplementary Table S2 (available in IJSEM Online). All of these strains contained $\mathrm{C}_{18: 1} \omega 9 c(35-51 \%)$ and $\mathrm{C}_{18: 1} \omega 9 c$ DMA $(25-37 \%)$ as the predominant fatty acids. The fatty acid profile of strain YIT $12063^{\mathrm{T}}$ was very similar to that of $C$. aerofaciens and that of strain YIT 12064 was similar to those of $C$. intestinalis and C. stercoris. Respiratory quinones were not detected in strains YIT $12063^{\mathrm{T}}$, YIT 12064 or the type strains of $C$. aerofaciens, $C$. intestinalis and C. stercoris.

Regions of the 16S rRNA genes of YIT $12063^{\mathrm{T}}$ (1491 bp) and YIT 12064 (1460 bp) were sequenced. They shared $>99 \% 16 \mathrm{~S}$ rRNA gene sequence similarity and $>97$ $\pm 1.8 \%$ DNA-DNA relatedness. Although their phenotypic characteristics were also very similar, they could be discriminated by RAPD fingerprinting (Supplementary Fig. S1, available in IJSEM Online). Sequence database searches of recognized taxa revealed that strains YIT $12063^{\mathrm{T}}$ and YIT 12064 were related most closely to species of the genus Collinsella, with $16 \mathrm{~S}$ rRNA gene sequence similarities of $93.8,95.0$ and $95.1 \%$ to the type strains of C. aerofaciens, C. intestinalis and C. stercoris, respectively (Fig. 1).

However, the most similar 16S rRNA gene sequences were derived from uncultured bacterial clones. At the time of writing, the 16S rRNA gene sequences of nine uncultured bacterial clones deposited in GenBank/EMBL/DDBJ had $>99 \%$ similarity to that of strain YIT $12063^{\mathrm{T}}$. Some of these were faecal uncultured clones from a human (GenBank accession no. EF399657), reported by Li et al. (2008), an armadillo (accession no. EU467584), a squirrel (accession no. EU779003) and a lion (accession no. EU776612) reported by Ley et al. (2008) (Fig. 1).

Table 2 shows the characteristics that can be used to differentiate between isolates YIT $12063^{\mathrm{T}}$ and YIT 12064 and members of the genus Collinsella. The DNA G+C contents of strains YIT $12063^{\mathrm{T}}$ and YIT 12064 were 60.8 and $61.0 \mathrm{~mol} \%$, respectively.

Although there is no direct evidence that members of the species represented by strains YIT $12062^{\mathrm{T}}$ and YIT $12063^{\mathrm{T}}$ have been isolated from human faeces as common members of the human indigenous microbiota, as described above, evidence in favour of this comes from the fact that many clones from uncultured human intestinal bacteria with highly similar 16S rRNA gene sequences to those of strains YIT $12062^{\mathrm{T}}$ and YIT $12063^{\mathrm{T}}$ have been deposited in GenBank/EMBL/DDBJ (Fig. 1).

It is evident from the results presented that strains YIT $12062^{\mathrm{T}}$ and YIT $12063^{\mathrm{T}}$ recovered from human faeces represent novel species within the genera Slackia and Collinsella, respectively, for which the names of Slackia piriformis sp. nov. and Collinsella tanakaei sp. nov. are proposed.

\section{Emended description of the genus Slackia Wade et al. (1999)}

The genus description is as given by Wade et al. (1999) with the addition that sensitivity to bile is variable and DNA G $+\mathrm{C}$ content is $58-64 \mathrm{~mol} \%$.

\section{Description of Slackia piriformis sp. nov.}

Slackia piriformis (pi.ri.for'mis. L. n. pirum pear; L. adj. suffix -formis -like, in the shape of; N.L. fem. adj. piriformis pear-shaped, referring to the cell shape).

Cells are Gram-positive, obligately anaerobic, non-motile, approximately $0.4-1.1 \times 0.9-2.6 \mu \mathrm{m}$ in size and form chains of pear-shaped to irregularly shaped rods. Colonies after 4 days of growth at $37^{\circ} \mathrm{C}$ on modified GAM agar under anaerobic conditions are $0.1-1.0 \mathrm{~mm}$ in diameter, translucent to beige and circular, with an uneven surface and irregular edges. Cells are asaccharolytic and weakly resistant to $20 \%$ bile. Negative for nitrate reduction, catalase, urease, oxidase, and hydrolysis of aesculin and gelatin. Indole is not produced. In the API test systems (API Rapid ID32A and API ZYM), positive reactions are obtained for alanine arylamidase, arginine dihydrolase, cystine arylamidase, glycine arylamidase, histidine arylamidase, leucine arylamidase, naphthol-ASBI-phosphohydrolase, phenylalanine arylamidase, proline arylamidase, serine arylamidase, tyrosine arylamidase and valine arylamidase, and a weakly positive reaction is observed for acid phosphatase; $N$-acetyl- $\beta$-glucosaminidase, alkaline phosphatase, $\alpha$-arabinosidase, chymotrypsin, esterase (C4), esterase lipase (C8), $\alpha$-fucosidase, $\alpha$-galactosidase, $\beta$-galactosidase, 6 -phospho- $\beta$-galactosidase, $\alpha$-glucosidase, $\beta$-glucosidase, $\beta$-glucuronidase, glutamic acid decarboxylase, glutamyl glutamic acid arylamidase, leucyl glycine arylamidase, lipase (C14), $\alpha$-mannosidase, pyroglutamic acid arylamidase and trypsin activities are not detected. The major cellular fatty acids are $\mathrm{C}_{18: 1} \omega 9 c$ and $\mathrm{C}_{18: 1} \omega 9 c$ DMA. Respiratory quinones are not detected.

The type strain is YIT $12062^{\mathrm{T}}\left(=\mathrm{DSM} 22477^{\mathrm{T}}=\mathrm{JCM}\right.$ $16070^{\mathrm{T}}$ ), isolated from human faeces. The DNA G $+\mathrm{C}$ content of the type strain is $58.3 \mathrm{~mol} \%$.

\section{Description of Collinsella tanakaei sp. nov.}

Collinsella tanakaei (ta.na.ka'e.i. N.L. masc. gen. n. tanakaei of Tanaka, to honour Ryuichiro Tanaka, a Japanese microbiologist, for his contribution to increased knowledge about human intestinal microbiota and probiotics).

Cells are Gram-positive, obligately anaerobic, non-motile, approximately $0.5-1.0 \times 1.0-3.3 \mu \mathrm{m}$ in size and occur singly or in long chains of short rods. Colonies after 4 days of growth at $37{ }^{\circ} \mathrm{C}$ on modified GAM agar under anaerobic conditions are $0.1-1.5 \mathrm{~mm}$ in diameter, entire, circular, beige or grey-beige, and opaque. The major end 
Table 2. Major characteristics of strains YIT $12063^{\top}$ and YIT 12064 and other members of the genus Collinsella

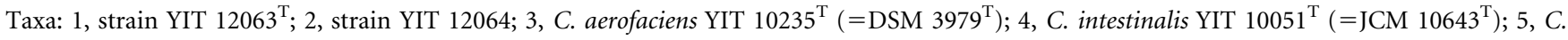
stercoris YIT $10052^{\mathrm{T}}\left(=\mathrm{JCM} 10641^{\mathrm{T}}\right)$. Data are from the present study unless otherwise indicated. + , Positive; - , negative; v, variable. In the API ZYM and Rapid ID32A test systems, all strains were positive for arginine arylamidase, arginine dihydrolase, glycine arylamidase, histidine arylamidase, leucine arylamidase, leucyl glycine arylamidase and naphthol-AS-BI-phosphohydrolase, but negative for $\alpha$-arabinosidase, chymotrypsin, cystine arylamidase, esterase (C4), esterase lipase (C8), $\alpha$-fucosidase, $\alpha$-galactosidase, glutamic acid decarboxylase, glutamyl glutamic acid arylamidase, lipase (C14), $\alpha$-mannosidase, phenylalanine arylamidase, pyroglutamic acid arylamidase, trypsin, urease and valine arylamidase. In the API 20A test system, all strains produced acid from glucose and D-mannose, but not from L-arabinose, glycerol, D-mannitol, melezitose, raffinose, L-rhamnose, D-sorbitol or D-xylose.

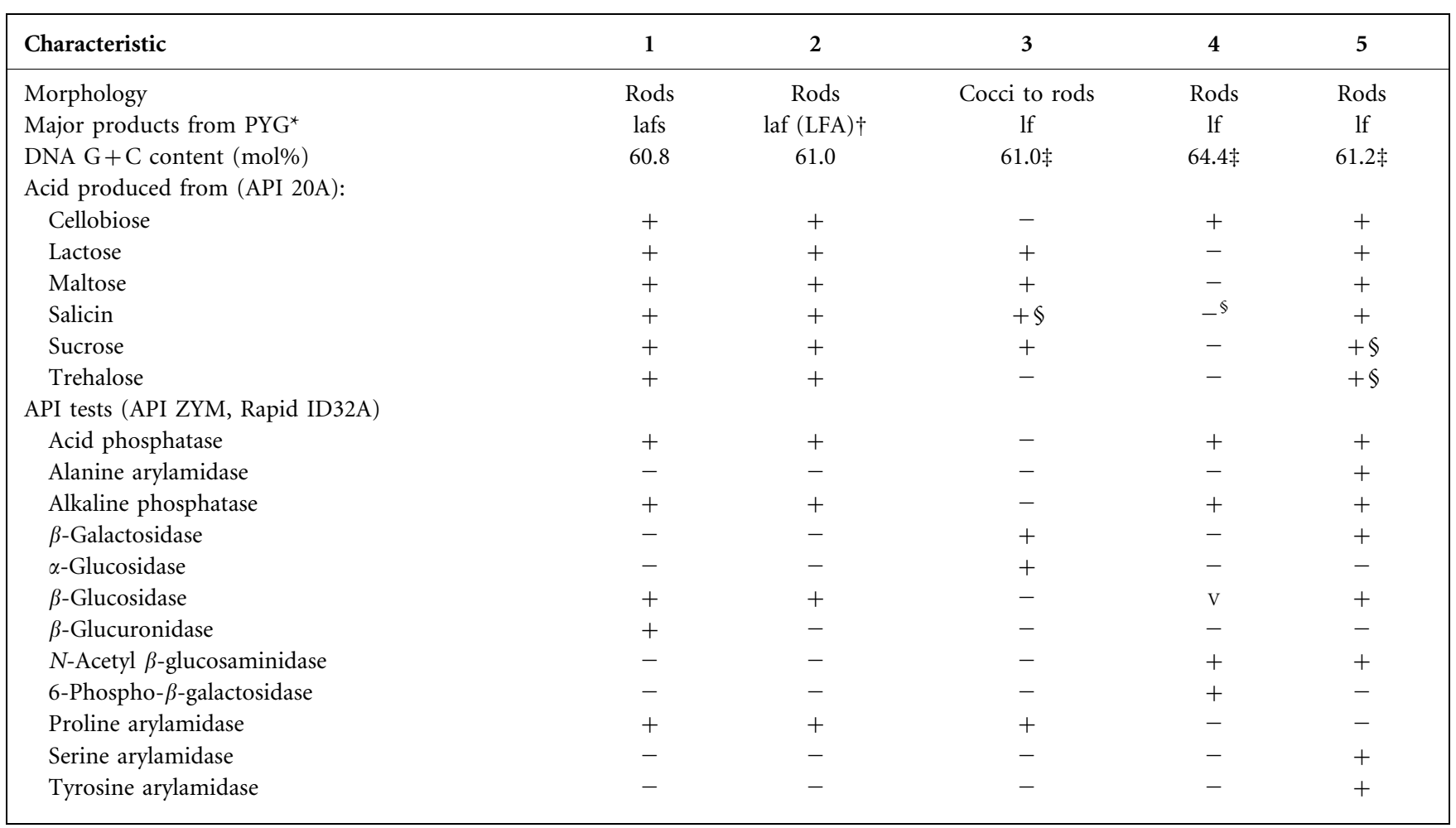

${ }^{\star}$ Lower-case letters indicate $<1$ mequiv. acid per $100 \mathrm{ml}$; a, acetic acid; l, lactic acid; s, succinic acid; f, formic acid. Data for strains YIT $12063^{\mathrm{T}}$ and YIT 12064 are from this study and those for C. aerofaciens, C. intestinalis and C. stercoris are from Kageyama et al. (1999) and Kageyama \& Benno (2000).

$\dagger$ Letters in parentheses indicate products formed when grown in GAM broth supplemented with $1 \%$ glucose (see text for details).

$\ddagger$ Data for DNA G + C content for C. aerofaciens are from Kageyama et al. (1999) and those for C. intestinalis and C. stercoris are from Kageyama \& Benno (2000).

§Data from this study (tested by using API 20A) were different from the published data (Kageyama et al., 1999 and Kageyama \& Benno, 2000, tested by using the conventional culture method as described by Holdeman et al., 1977).

products of glucose metabolism are lactic, acetic and formic acids. Cells are resistant to $20 \%$ bile and positive for aesculin hydrolysis. Nitrate reduction, indole, oxidase, urease, catalase and gelatin hydrolysis are negative. In API 20A tests, positive for acid production from cellobiose, glucose, lactose, maltose, D-mannose, salicin, sucrose and trehalose; acid is not produced from L-arabinose, glycerol, D-mannitol, melezitose, raffinose, L-rhamnose, D-sorbitol or D-xylose. By using the API Rapid ID32A and API ZYM test systems, acid phosphatase, alkaline phosphatase, arginine arylamidase, arginine dihydrolase, $\beta$-glucosidase, $\beta$-glucuronidase, glycine arylamidase, histidine arylamidase, leucine arylamidase, leucyl glycine arylamidase,
naphthol-AS-BI-phosphohydrolase and proline arylamidase activities are detected; $N$-acetyl- $\beta$-glucosaminidase, alanine arylamidase, $\alpha$-arabinosidase, chymotrypsin, cystine arylamidase, esterase lipase (C8), esterase (C4), $\alpha$ fucosidase, $\alpha$-galactosidase, $\beta$-galactosidase, 6 -phospho- $\beta$ galactosidase, $\alpha$-glucosidase, glutamic acid decarboxylase, glutamyl glutamic acid arylamidase, lipase (C14), $\alpha-$ mannosidase, phenylalanine arylamidase, pyroglutamic acid arylamidase, serine arylamidase, trypsin, tyrosine arylamidase and valine arylamidase activities are not detected. The major cellular fatty acids are $\mathrm{C}_{18: 1} \omega 9 c$ and $\mathrm{C}_{18: 1} \omega 9 c$ DMA. Respiratory quinones are not detected. The DNA G + C content range is $60.8-61.0 \mathrm{~mol} \%$. 
The type strain is YIT $12063^{\mathrm{T}}\left(=\mathrm{DSM} 22478^{\mathrm{T}}=\mathrm{JCM}\right.$ $\left.16071^{\mathrm{T}}\right)$, isolated from human faeces. Strain YIT 12064 (=DSM 22514=JCM 16103) is also assigned to this species.

\section{Acknowledgements}

We are grateful to Dr Jean P. Euzéby of the Ecole Nationale Vétérinaire in Toulouse for his suggestions regarding the etymology of the species epithet. We thank H. Sakon and K. Manabe for their advice and help with the quinone analysis. We also thank Dr Haruji Sawada for his understanding and encouragement through our research activities.

\section{References}

Akopyanz, N., Bukanov, N. O., Westblom, T. U., Kresovich, S. \& Berg, D. E. (1992). DNA diversity among clinical isolates of Helicobacter pylori detected by PCR-based RAPD fingerprinting. Nucleic Acids Res 20, 5137-5142.

Chonan, O., Matsumoto, K. \& Watanuki, M. (1995). Effect of galactooligosaccharides on calcium absorption and preventing bone loss in ovariectomized rats. Biosci Biotechnol Biochem 59, 236-239.

Ezaki, T., Hashimoto, Y. \& Yabuuchi, E. (1989). Fluorometric deoxyribonucleic acid-deoxyribonucleic acid hybridization in microdilution wells as an alternative to membrane filter hybridization in which radioisotopes are used to determine genetic relatedness among bacterial strains. Int J Syst Bacteriol 39, 224-229.

Ezaki, T., Saidi, S. M., Liu, S. L., Hashimoto, Y., Yamamoto, H. \& Yabuuchi, E. (1990). Rapid procedure to determine the DNA base composition from small amounts of gram-positive bacteria. FEMS Microbiol Lett 55, 127-130.

Felsenstein, J. (2004). PHYLIP (phylogeny inference package) version 3.6. Distributed by the author. Department of Genome Sciences, University of Washington, Seattle, USA.

Guindon, S. \& Gascuel, O. (2003). A simple, fast, and accurate algorithm to estimate large phylogenies by maximum likelihood. Syst Biol 52, 696-704.

Harmsen, H. J. M., Wildeboer-Veloo, A. C. M., Grijpstra, J., Knol, J., Degener, J. E. \& Welling, G. W. (2000). Development of 16S rRNAbased probes for the Coriobacterium group and the Atopobium cluster and their application for enumeration of Coriobacteriaceae in human feces from volunteers of different age groups. Appl Environ Microbiol 66, 4523-4527.

Holdeman, L. V., Cato, E. P. \& Moore, W. E. C. (1977). Anaerobe Laboratory Manual, 4th edn. Blacksburg, VA: Virginia Polytechnic Institute and State University.

Jin, J.-S., Kitahara, M., Sakamoto, M., Hattori, M. \& Benno, Y. (2010). Slackia equolifaciens sp. nov., a human intestinal bacterium capable of producing equol. Int J Syst Evol Microbiol 60, 1721-1724.

Kageyama, A. \& Benno, Y. (2000). Emendation of genus Collinsella and proposal of Collinsella stercoris sp. nov. and Collinsella intestinalis sp. nov. Int J Syst Evol Microbiol 50, 1767-1774.

Kageyama, A., Benno, Y. \& Nakase, T. (1999). Phylogenetic and phenotypic evidence for the transfer of Eubacterium aerofaciens to the genus Collinsella as Collinsella aerofaciens gen. nov., comb. nov. Int $J$ Syst Bacteriol 49, 557-565.

Kassinen, A., Krogius-Kurikka, L., Mäkivuokko, H., Rinttilä, T., Paulin, L., Corander, J., Malinen, E., Apajalahti, J. \& Palva, A. (2007). The fecal microbiota of irritable bowel syndrome patients differs significantly from that of healthy subjects. Gastroenterology $133,24-33$.

Katsuta, A., Adachi, K., Matsuda, S., Shizuri, Y. \& Kasai, K. (2005). Ferrimonas marina sp. nov. Int J Syst Evol Microbiol 55, 1851-1855.

Kimura, M. (1980). A simple method for estimating evolutionary rates of base substitutions through comparative studies of nucleotide sequences. J Mol Evol 16, 111-120.

Komagata, K. \& Suzuki, K. (1987). Lipid and cell-wall analysis in bacterial systematics. Methods Microbiol 19, 161-207.

Kuykendall, L. D., Roy, M. A., O’Neill, J. J. \& Devine, T. E. (1988). Fatty acids, antibiotic resistance, and deoxyribonucleic acid homology groups of Bradyrhizobium japonicum. Int J Syst Bacteriol 38, 358361.

Lanigan, G. W. (1976). Peptococcus heliotrinreducans, sp. nov., a cytochrome-producing anaerobe which metabolizes pyrrolizidine alkaloids. J Gen Microbiol 94, 1-10.

Lawson, P. A., Greetham, H. L., Gibson, G. R., Giffard, C., Falsen, E. \& Collins, M. D. (2005). Slackia faecicanis sp. nov., isolated from canine faeces. Int J Syst Evol Microbiol 55, 1243-1246.

Ley, R. E., Turnbaugh, P. J., Klein, S. \& Gordon, J. I. (2006). Microbial ecology: human gut microbes associated with obesity. Nature 444, 1022-1023.

Ley, R. E., Hamady, M., Lozupone, C., Turnbaugh, P. J., Ramey, R. R., Bircher, J. S., Schlegel, M. L., Tucker, T. A., Schrenzel, M. D. \& other authors (2008). Evolution of mammals and their gut microbes. Science 320, 1647-1651.

Li, M., Wang, B., Zhang, M., Rantalainen, M., Wang, S., Zhou, H., Zhang, Y., Shen, J., Pang, X. \& other authors (2008). Symbiotic gut microbes modulate human metabolic phenotypes. Proc Natl Acad Sci U S A 105, 2117-2122.

Lipman, D. J. \& Pearson, W. R. (1985). Rapid and sensitive protein similarity searches. Science 227, 1435-1441.

Matsuki, T., Watanabe, K., Fujimoto, J., Miyamoto, Y., Takada, T., Matsumoto, K., Oyaizu, H. \& Tanaka, R. (2002). Development of $16 \mathrm{~S}$ rRNA-gene-targeted group-specific primers for the detection and identification of predominant bacteria in human feces. Appl Environ Microbiol 68, 5445-5451.

Matthies, A., Blaut, M. \& Braune, A. (2009). Isolation of a human intestinal bacterium capable of daidzein and genistein conversion. Appl Environ Microbiol 75, 1740-1744.

Miller, L. T. (1982). Single derivatization method for routine analysis of bacterial whole-cell fatty acid methyl esters, including hydroxy acids. J Clin Microbiol 16, 584-586.

Miyake, T., Watanabe, K., Watanabe, T. \& Oyaizu, H. (1998). Phylogenetic analysis of the genus Bifidobacterium and related genera based on 16S rDNA sequences. Microbiol Immunol 42, 661-667.

Morotomi, M., Nagai, F., Sakon, H. \& Tanaka, R. (2008). Dialister succinatiphilus sp. nov. and Barnesiella intestinihominis sp. nov., isolated from human faeces. Int J Syst Evol Microbiol 58, 2716-2720.

Morotomi, M., Nagai, F., Sakon, H. \& Tanaka, R. (2009). Paraprevotella clara gen. nov. sp. nov., and Paraprevotella xylaniphila sp. nov., new members of the family 'Prevotellaceae' isolated from human faeces. Int J Syst Evol Microbiol 59, 1895-1900.

Morotomi, M., Nagai, F., Watanabe, Y. \& Tanaka, R. (2010). Succinatimonas hippei gen. nov., sp. nov., isolated from human faeces. Int J Syst Evol Microbiol 60, 1788-1793.

Nagai, F., Morotomi, M., Sakon, H. \& Tanaka, R. (2009). Parasutterella excrementihominis gen. nov., sp. nov., a novel member of the family Alcaligenaceae isolated from human faeces. Int J Syst Evol Microbiol 59, 1793-1797. 
Nagai, F., Morotomi, M., Watanabe, Y., Sakon, H. \& Tanaka, R. (2010). Alistipes indistinctus sp. nov., and Odoribacter laneus sp. nov., common members of the human intestinal microbiota isolated from faeces. Int J Syst Evol Microbiol 60, 1296-1302.

Page, R. D. M. (1996). TreeView: an application to display phylogenetic trees on personal computers. Comput Appl Biosci 12, 357-358.

Poco, S. E., Jr, Nakazawa, F., Ikeda, T., Sato, M., Sato, T. \& Hoshino, E. (1996). Eubacterium exiguum sp. nov., isolated from human oral lesions. Int J Syst Bacteriol 46, 1120-1124.

Saitou, N. \& Nei, M. (1987). The neighbor-joining method: a new method for reconstructing phylogenetic trees. Mol Biol Evol 4, 406425.

Sakon, H., Nagai, F., Morotomi, M. \& Tanaka, R. (2008). Sutterella parvirubra sp. nov. and Megamonas funiformis sp. nov., isolated from human faeces. Int J Syst Evol Microbiol 58, 970-975.

Tamura, K., Dudley, J., Nei, M. \& Kumar, S. (2007). MEGA4: molecular evolutionary genetic analysis (MEGA) software version 4.0. Mol Biol Evol 24, 1596-1599.

Thompson, J. D., Gibson, T. J., Plewniak, F., Jeanmougin, F. \& Higgins, D. G. (1997). The CLUSTAL_X windows interface: flexible strategies for multiple sequence alignment aided by quality analysis tools. Nucleic Acids Res 25, 4876-4882.
Turnbaugh, P. J., Hamady, M., Yatsunenko, T., Cantarel, B. L., Duncan, A., Ley, R. E., Sogin, M. L., Jones, W. J., Roe, B. A. \& other authors (2009). A core gut microbiome in obese and lean twins. Nature 457, 480-484.

Wade, W. G., Downes, J., Dymock, D., Hiom, S. J., Weightman, A. J., Dewhirst, F. E., Paster, B. J., Tzellas, N. \& Coleman, B. (1999). The family Coriobacteriaceae: reclassification of Eubacterium exiguum (Poco et al. 1996) and Peptostreptococcus heliotrinreducens (Lanigan 1976) as Slackia exigua gen. nov., comb. nov. and Slackia heliotrinireducens gen. nov., comb. nov., and Eubacterium lentum (Prevot 1938) as Eggerthella lenta gen. nov., comb. nov. Int J Syst Bacteriol 49, 595-600.

Wang, R. F., Beggs, M. L., Erickson, B. D. \& Cerniglia, C. E. (2004). DNA microarray analysis of predominant human intestinal bacteria in fecal samples. Mol Cell Probes 18, 223-234.

Watanabe, Y., Nagai, F., Morotomi, M., Sakon, H. \& Tanaka, R. (2010). Bacteroides clarus sp. nov., Bacteroides fluxus sp. nov. and Bacteroides oleiciplenus sp. nov., isolated from human faeces. Int J Syst Evol Microbiol 60, 1864-1869.

Yuki, N., Shimazaki, T., Kushiro, A., Watanabe, K., Uchida, K., Yuyama, T. \& Morotomi, M. (2000). Colonization of the stratified squamous epithelium of the non-secreting area of horse stomach by lactobacilli. Appl Environ Microbiol 66, 5030-5034. 